\title{
São Gonçalo, Divisão do Trabalho na Metrópole e a Formação da Nova Periferia Metropolitana.
}

\author{
Daniel Pereira Rosa. \\ Email: daniel_uerj@hotmail.com \\ *Mestre em Geografia \\ Prof. Substituto ; UERJ-FFP \\ Prof. Titular ; FEUDUC.
}

\section{Resumo.}

Neste artigo refletimos sobre as mudanças ocorridas no espaço de São Gonçalo (RJ) e discutimos as projeções para o projeto de cidade em curso em um momento em que devido a fatores como a reestruturação produtiva, a maior seletividade do capital, somados à uma mudança de perfil do habitante gonçalense, nota-se uma organização do espaço que atenda à uma maior fatia da população tornadas consumidoras de produtos imobiliários e bens de consumo não -duráveis. Pensamos então nas causas e conseqüências desta mudança do que chamamos de Nova Periferia Metropolitana para acentuar a diferença deste espaço, com o conceito outrora adotado de que os municípios da periferia metropolitana fluminense cumpriam apenas o papel de reserva de mão-de-obra não qualificada para a cidade do Rio de Janeiro e para a antiga capital fluminense, Niterói.

Fato é que a cidade de São Gonçalo ainda enfrenta desafios para que o espaço seja promotor de melhorias sociais sobretudo em um momento em que 'cidadania' é cada vez mais forjada enquanto consumo.Não negamos a condição periférica mas através da hierarquia urbana, do planejamento citadino e dos novos empreendimentos, buscamos elementos para análise do que significado destas mudanças nitidamente em curso.

\section{Introdução.}

Entre as diversas possibilidades de análise e abordagem sobre a produção do espaço urbano, chama-nos atenção a diversidade de estudos que tratam da fragmentação e da articulação das áreas urbanas.

Pensamos que 'todo 'problema urbano' se define estruturalmente por seu lugar na conjuntura de um dado sistema urbano, por sua significação social e seu tratamento na prática de que faz parte" (CASTELLS, 1983, p. 375) e na medida em que cidade torna-se urbana, primeiramente valendo-se de fatores como aglomeração e aumento da circulação e posteriormente, da mudança de sua estrutura e função, é estabelecida uma relação entre as demandas do 


\section{REVISTA TAMOIOS}

modo de produção capitalista e a materialidade do espaço enquanto formaconteúdo.

Com o aumento da interdependência entre o urbano e as atividades comerciais e industriais, percebe-se como conseqüência do processo, a fragmentação sob a forma de hierarquia entre os espaços, constituídos de processos cada vez mais imbricados que tendem simultaneamente a recriar hierarquias e anexar mais elementos à rede urbana que por sua vez, valendo-se da melhoria de estruturas e do aumento das condições de circulação (tanto de pessoas quanto de mercadorias),tornam mais densas as relações de produção no espaço, regidos pelo fenômeno urbano, onde concordamos com a proposição de que

A construção da problemática urbana, nesse contexto, envolve a articulação/ diferenciação cidade /urbano, iluminando o fato de que a cidade se prende à sua materialização concreta e no plano próximo, enquanto o urbano se refere à constituição de uma ordem distante que aponta para a constituição da sociedade urbana num contexto mundializado e, com isso, acentua a necessidade de se refletir no modo como se realiza o processo sócio espacial hoje" (CARLOS, 1999, p.178).

O fato é que nos últimos 20 anos o espaço urbano das cidades motivou estudos pelas mais variadas demandas. Professores, pesquisadores e gestores debruçaram-se no esmiuçar de diversos temas. Em escala regional, a metrópole, as relações centro-periferia, a rede urbana, a divisão do trabalho e o processo de industrialização e mais recentemente a globalização, foram os temas-chave da questão urbana. Em escala local, vimos aumentar o foco e a curiosidade sobre a segregação, a fragmentação, a estrutura, a competição entre espaços, a produção de moradia e a corrida para atração de eventos, como temas de interesse cada vez mais recorrentes.

Entre estes temas, entendemos que três questões articulam o debate sobre o urbano abrangendo com maior ou menor ênfase, direta ou indiretamente alguns dos temas citados acima.

Neste sentido, elegemos a cidade, o planejamento e a hierarquia como temas que sintetizam questões que, ao mesmo tempo em que surgem revestidas de um novo sentido, denunciam em sua estrutura, a natureza do espaço enquanto condição e meio das relações de produção. 


\section{REVISTA TAMOIOS}

No entanto, é preciso refutar a construção teórica - metodológica que nos compele a estudar e conceber o espaço urbano (representado pela cidade), como expressão material pura e simples dos ajustes econômicos, pois apesar da questão do valor do espaço e de suas potencialidades frente ao capital, o espaço também é um produto social e desta forma, quando consideramos apenas os fatores da cidade que convergem para a produção de mais-valia , reduzimos nossas possibilidades de entender causas, conseqüências e implicações do fenômeno urbano.

Propomos não separar os temas, pois é possível entender que, na medida em que o capital é contemplado com maior seletividade conferida pela tecnologia e maior velocidade dos fluxos, esta flexibilidade volta-se para as cidades, que por sua vez, tendo ganhado mais autonomia política- administrativa, reverberam este movimento tornando-o cíclico, quando se voltam para competir cada vez mais por investimentos na falsa esperança de que estes, sejam os motores de um novo ciclo de investimentos benéficos à cidade e (mais utópico ainda), aos citadinos.

Esta competição traz ainda a ilusão de que estas benesses apenas seriam possíveis através do exercício do planejamento urbano, como elemento que propiciaria a captação e distribuição dos recursos recém chegados à cidade através da geração de eventos e da profusão de novos empreendimentos industriais ou comerciais.

Esta idéia vingou como discurso, mas não como elemento catalisador de transformações sociais reais na lógica capitalista de produção do espaço, o que já nos soa contraditório. Em primeiro lugar, por que questionamos veementemente a importância atribuída ao planejamento no momento atual da produção dos espaços citadinos, sobretudo os espaços das cidades em áreas metropolitanas.

E aqui aparece o terceiro elemento da tríade anteriormente citada. Tanto a competição por investimentos, quanto o planejamento enquanto discurso de legitimação desta fase atual da produção capitalista do espaço citadino tem em suas bases a idéia (que é real) de hierarquia entre as cidades e no caso, tomamos a metrópole do Rio de Janeiro, e mais especificamente o exemplo da cidade de São Gonçalo para exemplificar a questão, pois é justamente a sua condição periférica que encadeia o debate sobre as mudanças ocorridas na 


\section{REVISTA TAMOIOS}

organização do espaço de cidades periféricas, permitindo construir um grande questionamento que norteia esta reflexão: Existe uma nova periferia metropolitana?

E de fato, quais seriam os fatores condicionantes desta mudança, uma vez que ela se põe de forma dialética, na medida em que ela tem sido atribuída à uma nova condição deste espaço e também a um planejamento previamente executado.

Podemos então identificar estas mudanças e analisá-las tanto do ponto de vista do discurso do planejamento quanto das inferências que podemos fazer através da estrutura urbana.

\section{A hierarquia como ponto de partida e a condição periférica de São Gonçalo.}

Começando pela hierarquia, " [...] pois a própria existência de áreas metropolitanas num país já implica numa divisão inter-regional de trabalho" (1987, p.147) já que "a divisão territorial do trabalho, constitui um motor da vida social e da diferenciação espacial" (SANTOS, 1996 p.129), não por acaso elegemos o exemplo da cidade de São Gonçalo para pensar a configuração desta nova periferia metropolitana, uma vez que a metrópole Fluminense apresenta em sua divisão do trabalho, graus de concentração urbana muito elevados.

Percebida como cidade dormitório, sobretudo nos ciclos de intensa urbanização do centro metropolitano fluminense, recebendo migrantes, tanto do interior do estado do Rio de Janeiro, quanto forças de trabalho vindas do Norte-Nordeste do país e que não conseguiram se instalar ( ou se manter ) em uma metrópole de solo urbano muito caro, a evolução urbana de São Gonçalo ${ }^{i}$ assemelha-se ao processo ocorrido no recorte conhecido como baixada Fluminense, onde a expansão da linha férrea, aliada ao baixo valor dos terrenos (devido sobretudo à baixa oferta de transportes, saneamento e serviços públicos básicos), configurou uma periferia marcada por ser uma grande área fornecedora de mão-de-obra pouco qualificada para o centro metropolitano. 


\title{
REVISTA TAMOIOS
}

Cabe ressaltar que conceitualmente, entendemos periferia, como uma condição e não apenas enquanto distância do centro metropolitano. Se "morar na periferia é se condenar duas vezes à pobreza" (SANTOS, 1987, p. 115) é a observância das esferas de produção, circulação e consumo que não nos permite conceber os espaços periféricos apenas a partir da distância do centro mais dinâmico. Então, é a incipiente oferta de equipamentos públicos e suas respectivas funções sociais que nos permitem identificar estes espaços periféricos, conforme Souza (1998, p.09):

\begin{abstract}
A pobreza que se traduz no espaço urbano pelas habitações precárias, carência de equipamentos coletivos, periferias urbanas cada vez mais ampliadas e distantes, a impossibilidade da gestão urbana, a carência de recursos financeiros, a inadequação tecnológica, a especulação imobiliária e uma infinidade de dilemas que o capitalismo insiste em remediar.
\end{abstract}

Neste sentido, São Gonçalo tem seu espaço marcado pela noção de cidade-periférica. Mas o que nos chama atenção é o quanto esta percepção foi reforçada ao longo de sua história urbana, seja pelas pesquisas acadêmicas, pelos administradores e planejadores ou mesmo pelos órgãos oficiais, como os relatórios técnicos na última edição do seu plano diretor (2008).

Considerando então, uma urbanização fragmentada em que "estar distante é sinal de ser prejudicado" (SANTOS, 2004, p. 292), podemos exemplificar esta condição periférica, marcada pela articulação com o seu exterior e pela fragmentação intra-citadina.

Pensemos em alguns problemas identificados na cidade de São Gonçalo, que nos ajudam a sedimentar esta idéia como, por exemplo:

Ausência de hospital de grande porte, que atenda a população de população de $960.631^{\text {ii }}$

- Rede bancária rarefeita e concentrada nos logradouros que exercem alguma centralidade.

Vias marginais ou coletoras com pavimentação de má qualidade, ou incompletas.

Coleta de lixo irregular e incipiente

- Poluição visual nas principais vias da cidade. 


\section{REVISTA TAMOIOS}

- Sinalização inadequada de ruas e logradouros que dificultam a localização e entrega de correspondências.

O que soa estranho é a veemência da repetição por parte dos governos urbanos, da idéia de que os problemas de São Gonçalo vinham do processo de especialização da metrópole. Era a noção de que os espaços encontravam-se rigidamente articulados através da existência de uma hierarquia urbana. A metrópole seria responsável pela provisão de serviços de maior valor agregado e à periferia, caberia o papel de cidade - dormitório que abrigava o reservatório de mão-de-obra de trabalhadores com baixa qualificação. Esta situação ajudava a construir e sedimentar um diagnóstico depreciativo da cidade em proposições como a que segue abaixo:

Niterói, com um passado de capital, continua dependendo dos empregos do RIO, porém se beneficia de não ter que carregar o lastro de uma periferia essencialmente pobre, já que o município de São Gonçalo faz bem este papel, que em caráter normal gera pouco imposto e demanda muitos serviços. Vale aqui recorrer a São Paulo que ao instituir sua Região Metropolitana tinha em seu entorno um $A B C D$ que sempre produziu bens e gerou empregos de qualidade, em quantidade. (IPP, 2001)

Diante deste cenário, caberia ao citadino gonçalense buscar alternativas para ascensão socioeconômica, que implicava na maioria das vezes, - em caso de êxito, na mudança para bairros de melhor infra-estrutura, nas cidades de Niterói ou em alguns casos, da cidade do Rio de Janeiro.

Às periferias, cabia torcer por migalhas da larga fatia apropriada pelo núcleo metropolitano, respondendo às demandas de seus citadinos sempre com o discurso de que havia poucos recursos disponíveis, já que os grandes capitais localizavam-se no centro metropolitano.

O quadro da cidade como um espaço periférico da metrópole Fluminense é assim composto, segundo o relatório técnico de seu próprio Plano diretor (2008):

1- "O município possui grandes redes de supermercados, contudo, encontra-se fora de São Gonçalo o comércio varejista que atende à maioria da população assim com as opções de entretenimento e lazer. Tal demanda satisfaz-se principalmente em Niterói e cria um 


\section{REVISTA TAMOIOS}

quadro pouco vantajoso na medida em que a renda deste consumo é deixada em outras cidades."

2- "Com uma grande população de baixa renda, São Gonçalo parece uma cidade inacabada. Em decorrência do alto grau de pobreza, o processo de "autoconstrução" das moradias é o mais utilizado..."

3- "É nesta cidade dormitório, com largas faixas de ocupações subnormais, grande contingente de população de baixa renda, mão-de-obra farta e com postos de trabalho mais qualificados fora do município, que alguns projetos se colocam dentro das expectativas da população de São Gonçalo: a necessidade de consolidar o desenvolvimento local..."

Segundo o Relatório Técnico do Plano Diretor de São Gonçalo, constariam ainda como sérios problemas diagnosticados na cidade:

- $\quad$ O baixo poder aquisitivo da população. (PD, 2008, p.46)

- A cidade "não cria no cidadão o vínculo com o espaço físico, ou seja, o orgulho de ser e de morar em São Gonçalo; (PD, 2008, p.47)

Estas proposições dão a idéia de uma economia estagnada, sem perspectivas, cujo crescimento e desenvolvimento dependia exclusivamente das "sobras" da expansão metropolitana e também do dinamismo de Niterói, antiga capital fluminense devido à centralidade que exerce no Leste Metropolitano.

\section{A supervalorização do planejamento.}

Neste cenário, os principais agentes de produção do espaço, junto com o poder municipal, cunharam o discurso de que pobreza da cidade devia-se a falta de planejamento e dois fatores contribuíram para este pensamento, talvez, indo de encontro à proposição de Modesto (2006, p.311), de que existam, "práticas espaciais produzidas pelo poder político na consolidação de uma rede política que procuram fazer a manutenção de determinados grupos no poder".

O primeiro dos fatores que trouxe o debate do planejamento, foi a lei 10.257 de 2001,que instituía a exigência do Plano Diretor para cidades com mais de 20.000 habitantes. O segundo elemento é a maior seletividade do capital, que fomentava a competição entre as cidades por investimentos. Neste caso, o anúncio da instalação do Complexo Petroquímico do Estado do Rio de 


\section{REVISTA TAMOIOS}

Janeiro no município de Itaboraí ,bem como a instalação do seu centro de inteligência na cidade de São Gonçalo, criaram a atmosfera favorável ao discurso de que era necessário planejar a cidade.

Mas é necessário lembrar, que tanto o plano diretor, quanto o planejamento como exercício técnico e político, são instrumentos que sempre estiveram à disposição dos governos e, sobretudo, falharam na sua concepção.

O plano diretor não serviu a um mecanismo de maior equidade do espaço, da mesma forma como o planejamento serviu aos interesses dos grupos que exerciam o poder e não primaram pelas questões principais colocadas, pela Reforma Urbana, como questões de moradia e saneamento.

O que se teve no planejamento do espaço citadino, foi uma abordagem economicista, disseminando o consenso de que com o planejamento, investimentos viriam e a maior circulação de bens, serviços e mercadorias seriam responsáveis pela melhoria, tanto das condições gerais do emprego na cidade, quanto da melhoria da estrutura e serviços coletivos urbanos e consequentemente, das condições sociais e de reprodução da vida.

O planejamento não é uma prática inócua, mas é preciso fugir da armadilha de atribuir-Ihe esperanças de equidade espacial, afinal, como nos lembra Carlos (2009), ao afirmar que a fé cega no planejamento é um desafio real que precisa ser enfrentado pela Geografia Crítica.

Estabelecendo a crítica ao planejamento e à forma como ele tem sido abordado nos estudos urbanos, concordamos com a proposição de Carlos (2009) de que o planejamento não é distributivo, é um instrumento técnico e político que está a serviço do capital, ele apenas faz ajustes e busca atenuar o agravamento da fragmentação do espaço.

Se não é o planejamento a causa da mudança, - aqui já admitindo que ela está em curso, quais seriam os elementos que indicam uma mudança de condição em algumas das cidades da periferia metropolitana fluminense?

\section{Hipóteses para uma mudança em curso.}

Para debater as mudanças no espaço da periferia metropolitana fluminense é necessário retomar uma proposição elementar. Uma contradição resultante do movimento de apropriação do espaço pelo capital, que nos 


\section{REVISTA TAMOIOS}

lembra o quanto nossas cidades são muito díspares em termos de estrutura e oferta de serviços públicos.

De fato,quando percebemos a hierarquia urbana, os movimentos de descentralização e desconcentração de fixos e a redistribuição de fluxos sobretudo em um momento de reestruturação produtiva nos municípios fluminenses, estamos situando nossa análise em um contexto que tem como força motriz a diferenciação espacial provocada pela expansão e reprodução capitalista do espaço.

Mesmo considerando, no caso do Rio de Janeiro, as peculiaridades que a tornam uma metrópole com maior poder concentrador, nos últimos 20 anos temos acompanhado transformações socioeconômicas - condicionadas pelo e refletidas no espaço, de cidades que não estavam à margem do processo, mas cumpriam um papel satélite e secundário no processo de produção.

Mudanças no perfil da população, na organização do espaço e na orientação do planejamento, voltado agora para a inserção destas cidades ainda periféricas, em uma nova divisão do trabalho na metrópole que se faz perceber também no quotidiano citadino.

Vale ressaltar, que em trabalho anterior ${ }^{1}$, já havíamos atentado para as mudanças ocorridas no espaço urbano da cidade de São Gonçalo. O que difere do momento anterior é que na etapa anterior propomos uma relação entre o discurso da pobreza e a fomentação de capital político e formação de consensos para a criação de organização do espaço citadino que favoreça os agentes hegemônicos de produção do espaço.

Neste caso, - capitaneados pelo anúncio do COMPERJ, as esperanças de uma cidade caracterizada como cidade-dormitório (argumento rechaçado neste trabalho), criaram na sociedade uma aceitação ampla de mudanças na organização espacial que seriam para preparar a cidade para receber o empreendimento e não perder a oportunidade de geração de empregos.

Deu-se assim a corrida para "planejar a cidade', período que coincidiu com os debates sobre a elaboração da nova edição do seu plano diretor (2008).

\footnotetext{
${ }^{1}$ ROSA, Daniel Pereira .Política urbana, planejamento, fragmentação e articulação: São Gonçalo e as transformações no espaço da cidade periférica . Dissertação de mestrado. UERJ. 2010. $147 \mathrm{f}$.
} 


\section{REVISTA TAMOIOS}

Tanto antes, quanto no momento atual, identificamos que alguns fatores refutam a idéia de uma São Gonçalo essencialmente pobre graças à sua condição periférica. O que difere no momento atual, é que antes, concentramos a análise em torno do que havia de pertinente ou não sobre o discurso da pobreza e, a quem servia este discurso no projeto e planejamento da cidade. No momento atual, admitindo que apesar das carências de uma periferia sob a influência de uma metrópole tão concentradora como o Rio de Janeiro existe um dinamismo econômico. Então nos debruçamos em entender o sentido deste dinamismo, as causas da mudança e os rumos que ela indica, num cenário que primeiramente e em hipótese, chamamos de nova periferia metropolitana.

Concomitante ao anúncio do COMPERJ, a primeira década dos anos 2000 traçaram um cenário favorável para uma nova distribuição de papéis na metrópole fluminense. Entre fatores de ordem local e processos em maior escala, citamos entre estas possibilidades:

- A reestruturação produtiva da produção industrial fluminense sobretudo na região metropolitana, onde o leste metropolitano ganha destaca-se recebendo atividades de médio e grande porte, fomentando a geração de empregos.

- A estabilidade monetária e a expansão do crédito direto e do crédito imobiliário, permitindo uma expansão tanto da aquisição de imóveis como de bens de consumo como automóveis e eletrodomésticos.

- Indiretamente o fator acima fomenta uma rede de serviços que de suporte à manutenção do maior volume de bens de consumo duráveis.

- A distribuição dos Royalties da extração do petróleo que fomentou um aumento de arrecadação dos municípios incluindo os da metrópole fluminense.

- A reorganização da indústria naval que beneficiou diretamente as cidades de Niterói e São Gonçalo.

Em longo prazo será necessário investigar o impacto destas mudanças na distribuição de classes de renda em São Gonçalo, mas é pertinente supor , que a expansão do crédito, que afeta diretamente o consumo, aumenta também a arrecadação de impostos, onde o ICMS,ISS e o IPVA foram os que mais receberam incremento. 


\section{REVISTA TAMOIOS}

Assistimos então ao aumento da classe média residente na periferia metropolitana e a expansão, tanto do mercado imobiliário, quanto do mercado de serviços comprova esta hipótese.

São Gonçalo recebeu nos últimos 6 anos, seu primeiro e o segundo shopping Center. Recebeu o centro de inteligência do COMPERJ, melhorias no serviço de telefonia e expansão da internet banda larga bem como o serviço de televisão por assinatura.

Além disso, podemos citar serviços de saúde com incremento de estabelecimentos de exames laboratoriais, estabelecimentos de clínica médica, provavelmente ofertados à classe média da periferia metropolitana, que com o aumento da renda teve maior acesso aos planos de saúde de empresas privadas.

Outro indicativo de grande vulto e menos sutil é a chegada à cidade dos condomínios sob o conceito de bairro planejado. Ainda é cedo para argumentar o que significa a expansão da modalidade de condomínios para a periferia metropolitana, mas o que em princípio chama atenção é a presença de consumidores para este tipo de empreendimento, sinalizando tanto o peso desta classe média na cidade como também um recuo da 'evasão' desta mesma classe para a cidade de Niterói.

Segundo o IQM-2005 São Gonçalo apresentara melhoras no que diz respeito à centralidade, vantagem locacional, qualificação de mão-de-obra e facilidades para negócios no período entre 1998- 2005.

O núcleo metropolitano tem se diversificado e o aumento dos indicadores de algumas cidades da periferia metropolitana não denotam perda de centralidade, mostrando que o desenvolvimento, mesmo em um contexto regional depende mais de forças endógenas do que da primazia urbana na metrópole.

Junto com Nova Iguaçu e Duque de Caxias, São Gonçalo aparece como periferia dinâmica e fortemente articulada com o núcleo e sua região, apresentando melhora nos indicadores sócio-econômicos assim definidos:

Duque de Caxias, São Gonçalo e Nova Iguaçu retratam as mudanças estruturais que estão ocorrendo no interior da Região Metropolitana. Consolidam-se como subcentros dinâmicos (vejam-se os investimentos 


\section{REVISTA TAMOIOS}

em shoppings-centers e grandes redes de supermercados), tornando a periferia da Região menos dependente do núcleo, isto é, mais autônoma, inaugurando um desenho diferente de relacionamento centro-periferia. Esses três municípios colocam-se entre os de melhores posições com relação à Centralidade.

A posição de São Gonçalo é assim comentada pelo índice:

São Gonçalo subiu 25 posições no ranking, devido principalmente a Facilidades para negócios, Qualificação da mão-de-obra e Cidadania, destacando-se o aumento do número de terminais telefônicos instalados, de matrículas em cursos técnicos de segundo grau e de policiais civis e militares. Acrescente-se também 0 aumento do número de agências bancárias, de agências e postos dos Correios, bem como de matrículas no ensino básico, além da existência de Balcão SEBRAE e do PROCON e Defensoria Pública.

Além disso, "São Gonçalo tem ainda o segundo parque industrial do estado no que se refere à diversificação, sendo ultrapassado somente pela capital" (FREIRE \& FREIRE, 2006, p. 346).

Todos estes indicativos servem de ponto de partida para analisarmos a natureza das transformações evidentes em algumas cidades da periferia metropolitana.

\section{Conclusão}

Estas considerações mostram que já se pode falar em uma mudança significativa no perfil de algumas cidades da periferia metropolitana fluminense, dentre as quais São Gonçalo, junto com Niterói ao leste, e Nova Iguaçu e Duque de Caxias ao Oeste da Guanabara compõem um recorte que se destaca tanto pelo dinamismo econômico quanto por uma posição diferenciada daquilo que outrora se condicionou como cidade periférica.

$\mathrm{Na}$ medida em que criam-se cada vez mais "mercadorias que são estratégicas e políticas, como o caso específico do espaço" (CARLOS, 1999, p. 174), o aumento da classe média na periferia metropolitana é uma realidade que precisa ser relativizada no que tange às suas causas, mas em princípio o 


\section{REVISTA TAMOIOS}

planejamento urbano tem pouco a ver com este processo em que o maior dinamismo econômico tem fixado esta população na cidade, ofertando bens de consumo e serviços diferenciados que só eram encontrados anteriormente no centro metropolitano ou na cidade de Niterói.

A mudança de perfil aponta para um aumento do custo de reprodução social nestas cidades e a peculiaridade deste processo é o fato dele não ser homogêneo em escala metropolitana e por isto, seria incoerente citar uma nova periferia como um espaço ou um processo que abarca toda a periferia. Há uma melhoria de indicadores, mas estes, a nosso ver, refletem no espaço a materialização de um excedente de capital, agora aplicado nestas áreas e analisando a localização e distribuição dos novos empreendimentos, partimos da hipótese de que eles representam uma reprodução ampliada da divisão do trabalho na metrópole, onde se criam níveis intermediários entre as cidades.

Assim, a dinâmica de reprodução espacial da metrópole fluminense não diminui a sua centralidade mas recria divisões internas, onde algumas cidades alcançaram algum êxito na atração de capitais e na sua organização interna distanciando-se em termos de especialização produtiva dos municípios menos dinâmicos da periferia da metrópole fluminense.

Estas mudanças resultam na valorização de espaços, na criação de novos empreendimentos ao mesmo tempo em que a nova questão da classe média da periferia fluminense não suprime questões de organização do território que ainda não foram resolvidas, como a carência de moradias, a oferta desigual de transportes e a mobilidade na cidade, como temos acompanhado, por exemplo, no caso de São Gonçalo.

\section{Notas}

1 - A confusão mais freqüente é atribuir São Gonçalo como periferia da cidade de Niterói. A existência de áreas de ocupação da classe média ou ainda, uma área de ricos auto-segregados, ajuda a marcar a identidade niteroiense, ainda ressentida da perda da capital estadual, que se deu no plano políticoadministrativo, mas que não é esquecida, devido também à permanência de formas urbanas que associam a experiência citadina com o período em que vigorou a sua capitalidade, coisa que não acontece com São Gonçalo.

2 - População recenseada e estimada em 2007. Fundação Cide, 2008. 


\section{Referências:}

ARANTES, Otília. Uma estratégia fatal: a cultura nas novas gestões urbanas. In: ARANTES, Otília; VAINER, Carlos.; MARICATO, Ermína.(org.) A cidade do pensamento único: desmanchando consensos. Petrópolis, RJ: Vozes, 2000.

CARLOS, Ana Fani Alessandri. O consumo do espaço. In: Novos caminhos da Geografia, São Paulo: Editora Contexto, 1999.

O Espaço Urbano: Novos Escritos sobre a Cidade. São Paulo: Labur Edições, 2007.

\section{A "ilusão" da transparência do espaço e}

a "fé cega" no planejamento urbano: os desafios de uma geografia urbana crítica. Conferência de abertura . SIMPURB. 2009.

CASTELLS, Manuel. A questão urbana. Paz e Terra S.A, 1983.

Fundação CIDE. Dados de Referência. Rio de Janeiro, 2008. Índice de Qualidade dos Municípios. Rio de Janeiro, 2005.

FREIRE, Désirée Guichard \& FREIRE Denise. Consolidação de São Gonçalo (RJ) na periferia metropolitana e produção industrial: novas questões para a reflexão. In: Metrópole: governo, sociedade e território. DA SILVA, Cátia Antônia; FREIRE, Désirée Guichard; DE OLIVEIRA, Floriano José Godinho (orgs). Rio de Janeiro: DP\&A: FAPERJ, 2006.

HARVEY, David. Condição Pós-Moderna: uma pesquisa sobre as origens da mudança cultural. São Paulo: Loyola, 1989.

2005.

. A produção capitalista do espaço. São Paulo: Annablume,

INSTITUTO PEREIRA PASSOS. O Rio e sua região metropolitana- Coleção Estudos da Cidade, Rio de Janeiro, 2001.

MODESTO, Nilo Sérgio D'Ávila. As práticas espaciais do poder político em São Gonçalo. In: Metrópole: governo, sociedade e território. DA SILVA, Cátia Antônia ; FREIRE, Désirée Guichard; DE OLIVEIRA, Floriano José Godinho (orgs). Rio de Janeiro: DP\&A: FAPERJ, 2006.

OLIVEIRA, Floriano José Godinho de. Reestruturação produtiva e regionalização da economia no território fluminense. Tese de Mestrado. São Paulo: USP, 2003.

PREFEITURA MUNICIPAL DE SÃO GONÇALO \& TECNHUM CONSULTORIA, Relatório Técnico para Elaboração do Plano Diretor, 2008. 


\section{REVISTA TAMOIOS}

ROSA, Daniel Pereira .Política urbana, planejamento, fragmentação e articulação: São Gonçalo e as transformações no espaço da cidade periférica. Dissertação (Mestrado) - Universidade do Estado do Rio de Janeiro, Instituto de Geografia. 2010.

SANTOS, Milton. A urbanização brasileira. 3aㅡ Ed. São Paulo: Hucitec, 1993.

. A natureza do espaço. São Paulo: Hucitec, 1996.

O espaço dividido. Os dois circuitos da economia urbana dos países subdesenvolvidos. São Paulo: Edusp, 2004. 